\title{
Vibrios patogênicos em ostras (Crassostrea rhizophorae) servidas em restaurantes no Rio de Janeiro: um alerta para a Saúde Pública
}

\author{
Pathogenic Vibrios in oysters (Crassostrea rhizophorae) \\ served at restaurants in Rio de Janeiro: a public health warning
}

\author{
Christiane Soares Pereira ${ }^{1}$, Célio Mauro Viana ${ }^{2}$ e Dália dos Prazeres Rodrigues ${ }^{1}$
}

\begin{abstract}
RESUMO
Avaliaram-se 40 amostras de ostras (Crassostrea rhizophorae) servidas in natura em 15 restaurantes da Cidade do Rio de Janeiro, a fim de investigar a presença de Vibrio spp. As amostras de ostras foram analisadas e submetidas a enriquecimento em água peptonada alcalina adicionada de 1 e $3 \%$ de $\mathrm{NaCl}$, incubadas a $37^{\circ} \mathrm{C}$ por 24 horas. Em seguida, os cultivos foram semeados em agar tiossulfato citrato bile sacarose $e$ as colônias suspeitas foram submetidas à caracterização bioquímica. Vibrio parahaemolyticus, Vibrio carchariae, Vibrio alginolyticus $e$ Vibrio vulnificus representaram as principais espécies (> 60\%) isoladas a partir das ostras in natura.
\end{abstract}

Palavras-chaves: Ostra. Vibrio sp. Sorotipos. Virulência. Saúde pública.

\section{ABSTRACT}

Forty oyster samples (Crassostrea rhizophorae) served raw in 15 restaurants in the city of Rio de Janeiro were evaluated in order to investigate the presence of Vibrio spp. The oyster samples were analyzed and subjected to enrichment in alkaline peptone water with the addition of 1 and $3 \% \mathrm{NaCl}$ and incubated at $37^{\circ} \mathrm{C}$ for 24 hours. Following this, the cultures were seeded onto thiosulfate citrate bile sucrose agar (TCBS) and the suspected colonies were subjected to biochemical characterization. Vibrio parahaemolyticus, Vibrio carchariae, Vibrio alginolyticus and Vibrio vulnificus were the main species (> 60\%) isolated from raw oysters.

Key-words: Oyster. Vibrio sp. Serotypes. Virulence. Public health.

0 consumo de moluscos bivalves marinhos é uma prática crescente em todas as regiões litorâneas do Brasil, devido às riquezas dos recursos naturais do ecossistema aquático. As ostras, Crassostrea rhizophorae, são geralmente consumidas in natura sem prévio cozimento adicionada de algumas gotas de limão. Essa característica de preparo do alimento torna-o um risco potencial para a saúde humana, pois os moluscos alimentam-se, por processo de filtração, de partículas e microrganismos em suspensão na água, permitindo a retenção e acúmulo de poluentes e bactérias patogênicas ${ }^{12}$.

Diversas espécies do gênero Vibrio têm sido reconhecidas como patógenos de interesse para o homem e isoladas de várias regiões costeiras de clima temperado e tropical em todo o mundo. A capacidade desses microrganismos em causar gastrenterite humana, sob a forma de surtos ou casos esporádicos associados ao consumo de moluscos in natura ou insuficientemente cozidos, aumenta sua importância para a Vigilância Sanitária de Alimentos $^{416}$.

No Brasil, estudos revelaram a prevalência de Vibrio parahaemolyticus, Vibrio carchariae, Vibrio alginolyticus e Vibrio vulnificus no ambiente aquático, particularmente salino e também a partir de alimentos de origem marinha como no caso das ostras. Ressalta-se que a frequiência de isolamento desses patógenos costuma ser mais elevada nos meses de verão, tanto nas regiões de clima temperado como tropical, sugerindo uma característica de sazonalidade ${ }^{1711517}$.

Considerando a relevância epidemiológica das espécies do gênero Vibrio associado ao consumo de moluscos bivalves sem cocção ou insuficientemente cozidos, objetivou-se na presente investigação avaliar a presença desses microrganismos em ostras

1. Laboratório de Enterobactérias, Departamento de Bacteriologia, Instituto Oswaldo Cruz, Fundação Oswaldo Cruz, Rio de Janeiro, RJ. 2. Laboratório de Microbiologia de Alimentos, Faculdade de Veterinária, Universidade Federal Fluminense, Niterói, RJ.

Endereço para correspondência: Dra. Christiane Soares Pereira. Deptº de Bacteriologia/IOC/FIOCRUZ. Av. Brasil 4365, sala 320, Manguinhos, 21045-900 Rio de Janeiro, RJ. Tel: $55212270-6565$ ramal 320

e-mail: chrisspm@ioc.fiocruz.br

Recebido para publicação em 3/1/2007

Aceito em 2/4/2007 
in natura, comercializadas em restaurantes da região litorânea da Cidade do Rio de Janeiro.

\section{MATERIAL E MÉTODOS}

Foram analisadas 40 amostras de ostras in natura, no período de julho de 1997 a fevereiro de 1998, adquiridas de 15 restaurantes localizados na região litorânea da Cidade do Rio de Janeiro. As ostras (12-15), com as valvas fechadas, foram acondicionadas no interior de embalagem de polietileno devidamente identificada com etiqueta adesiva e transportadas em caixa de isopor contendo gelo reciclável a fim de manter a temperatura entre $6-10^{\circ} \mathrm{C}$. Em seguida, foram remetidas ao Laboratório de Enterobactérias, Departamento de Bacteriologia, Instituto Oswaldo Cruz (FIOCRUZ), para a realização das análises microbiológicas, dentro de um prazo que não ultrapassou duas horas.

0 procedimento utilizado inicialmente foi a lavagem das ostras em água corrente seguida de escovação vigorosa para retirada de sujidades retirando-se o excesso de umidade com auxílio de papel toalha. Em seguida, procedeu-se a seleção das amostras que consistiu na seleção de espécimes (12 a 15) cujas valvas estivessem fechadas. Posteriormente, as ostras foram abertas assepticamente recolhendo-se a parte corpórea e o líquido intervalvar em placa de petri. Foram pesadas $25 \mathrm{~g}$ de cada amostra a qual foram adicionadas $225 \mathrm{~mL}$ de solução salina tamponada (PBS) e, em seguida homogeneizadas em warning-blender (8.000 $\mathrm{rpm} / 1$ minuto). A partir de então foram retiradas alíquotas de $1 \mathrm{ml}$ dessas diluições as quais foram transferidas para tubos contendo água peptonada alcalina contendo $1 \%$ e $3 \%$ de cloreto de sódio $(\mathrm{NaCl})$ e incubados a temperatura de $37^{\circ} \mathrm{C}$ por um período de 18 a 24 horas. Após esse período, procedeu-se a semeadura em agar tiossulfato citrato bile sacarose (TCBS) e incubado a temperatura de $37^{\circ} \mathrm{C}$ por 24 horas. As colônias suspeitas (5 a 10) foram repicadas para meios de triagem (kligler iron agar e lysine iron agar) e agar nutriente acrescido de $1 \% \mathrm{de} \mathrm{NaCl}$. Após a seleção das cepas citocromo-oxidase positivas, foram realizados testes bioquímicos, baseados na resistência ao agente vibriostático 0/129 (fosfato de 2,4 diamino-6, diisopril-pteridina), produção de $\alpha$ nitrofenil- $\beta$-D galactosidase (ONPG), produção de acetoína no meio Voges-Proskauer, oxidação/fermentação da glicose, fermentação de sacarose, arabinose e manose e utilização de aminoácidos (lisina e ornitina descarboxilase e arginina dehidrolase) a fim de obter a identificação conclusiva das cepas isoladas 3 .

Todas as cepas de Vibrio parabaemolyticus isoladas foram submetidas ao teste de kanagawa em agar wagatsuma a fim de verificar sua patogenicidade, através da hemólise total dos eritrócitos humanos. Adicionalmente, foram caracterizadas antigenicamente para identificação do sorotipo. Essa prova foi realizada em placa de vidro para observação da aglutinação das cepas frente aos anti-soros e poli e monovalentes produzidos por Denka Seiken Co Lta, Tókio, Japão ${ }^{3}$.

\section{RESULTADOS E DISCUSSÃO}

$\mathrm{Na}$ presente investigação, a análise de 40 amostras de ostras comercializadas in natura em 15 restaurantes da região litorânea da Cidade do Rio de Janeiro permitiu o isolamento de 178 cepas de Vibrio sp distribuídas entre as seguintes espécies Vibrio parahaemolyticus, Vibrio carchariae, Vibrio alginolyticus, Vibrio vulnificus, Vibrio orientalis, Vibrio cincinnatiensis, Vibrio marinus e Vibrio fluvialis (Tabela 1). Foram isoladas 92 cepas a partir da água peptonada alcalina com $1 \%$ de cloreto de sódio (Vibrio parahaemolyticus: 50\%; Vibrio carchariae: 24\%; Vibrio vulnificus: 11\%; Vibrio alginolyticus: $9 \%$; Vibrio orientalis: 3\%; Vibriocincinnatiensis: 1\%; Vibrio marinus: 1\% e Vibriofluvialis: 1\%). Por outro lado, foram isoladas 86 cepas a partir daágua peptonada alcalina acrescida de 3\% de cloreto de sódio (Vibrio parahaemolyticus: 40\%; Vibrio carchariae: 29\%; Vibrio alginolyticus: $20 \%$; Vibrio vulnificus: 5\%; Vibrio orientalis: 5\% e Vibrio cincinnatiensis: $1 \%$. A diferença significativa entre os dois métodos de enriquecimento empregados permitiu observar a ocorrência da melhor caracterização das espécies de Vibrio spp isoladas a partir da água peptonada alcalina adicionada de $1 \%$ de cloreto de sódio.

Tabela 1 - Espécies de Vibrio spp caracterizadas a partir de ostras in natura, de acordo com a concentração salina do meio de enriquecimento empregado.

\begin{tabular}{|c|c|c|c|c|}
\hline \multirow[b]{3}{*}{ Espécies } & \multicolumn{4}{|c|}{ Água peptonada alcalina } \\
\hline & \multicolumn{2}{|c|}{$\mathrm{NaCl}(1 \%)$} & \multicolumn{2}{|c|}{$\mathrm{NaCl}(3 \%)$} \\
\hline & $\mathrm{n}^{0}$ & $\%$ & $\mathrm{n}^{0}$ & $\%$ \\
\hline Vibrio parahaemolyticus & 45 & 50,0 & 35 & 40,0 \\
\hline Vibrio carchariae & 22 & 24,0 & 25 & 29,0 \\
\hline Vibrio alginolyticus & 9 & 9,0 & 17 & 20,0 \\
\hline Vibrio vulnificus & 10 & 11,0 & 4 & 5,0 \\
\hline Vibrio orientalis & 3 & 3,0 & 4 & 5,0 \\
\hline Vibrio cincinnatiensis & 1 & 1,0 & 1 & 1,0 \\
\hline Vibrio marinus & 1 & 1,0 & - & \\
\hline Vibrio fluvialis & 1 & 1,0 & - & \\
\hline Total & 92 & 100,0 & 86 & 100,0 \\
\hline
\end{tabular}

Entre as espécies detectadas no presente estudo, Vibrio parahaemolyticus tem sido uma das mais estudadas, tendo em vista a ocorrência de surtos epidêmicos e casos isolados, particularmente após a ingestão de pescado e moluscos in natura ou insuficientemente cozidos. A maioria das cepas patogênicas possui a capacidade de produzir uma hemolisina termoestável (TDH/TRH) observada através do fênomeno de kanagawa e diretamente relacionada à determinação do quadro gastrentérico. Amostras de origem ambiental demonstram um percentual inferior ou igual a $1 \%$ de cepas Kanagawa positivas ${ }^{1613}$.

Com relação ao fenômeno de Kanagawa, é importante destacar que cerca de $90 \%$ das cepas isoladas de casos clínicos apresentam a hemolisina TDH, enquanto aquelas de origem ambiental apresentam um percentual de 1\% de cepas Kanagawa positivas ${ }^{8}$. Cabe acrescentar que na presente investigação, Vibrio parabaemolyticus representou a espécie mais freqüientemente isolada tanto a partir do meio APA 1\% quanto do APA 3\%, 
entretanto, quanto à avaliação do potencial patogênico através do fenômeno de kanagawa (KP), nenhuma das cepas isoladas apresentou resultado positivo, resultados que coadunam com aqueles apontados na literatura internacional ${ }^{28}$. Contudo, elevados percentuais de cepas com essa característica têm sido apontados em nosso meio entre isolados de outros tipos de pescado ${ }^{1011}$.

Das 80 cepas de Vibrioparabaemolyticus isoladas na presente investigação, quatro apresentaram-se rugosas impossibilitando sua caracterização antigênica. Foram caracterizados 32 sorotipos diferentes, assim distribuídos: 01:K12 (1), 01:K32 (1), 01: K33 (1), 02:K3 (4), 02:K28 (2), 02:K30 (1), 03:K5 (1), 03: K6 (1), 03:K30 (1), 03:K33 (2), 03:K57 (5), 03:K72 (3), 04: K12 (1), 04:K34 (2), 04:K42 (1), 05:K17 (6), 05:K25 (1), 08:K11 (1), 08:K39 (1),010:K25 (1), 010:K31 (1), 010:K52 (2), 010:K60 (1), 011:K19 (2), 011:K22 (1), 01:KUT (4), 02: KUT (3), 04:KUT (1), 08:KUT (1), 09:KUT (1), 010:KUT (18) e 011:KUT (4) (KUT- K untypable = não tipável). Foi observada uma distribuição dos sorotipos caracterizados que variou de acordo com a concentração salina do meio de enriquecimento empregado. Apenas os sorotipos 02:KUT, 03:K57 e 010:KUT foram caracterizados a partir do APA 1\% e do APA 3\% (Tabela 2). Esta particularidade pode estar associada à característica halofílica do microrganismo e salinidade do habitat de origem das ostras avaliadas neste estudo.

Destaca-se o isolamento do sorotipo 03: K6 que desde 1996 tem sido reportado como cepa pandêmica, particularmente na Ásia, Europa e Estados Unidos. Ressalta-se que alguns sorotipos isolados neste trabalho (01:KUT e 04:K12) têm sido considerados emergentes em diversas regiões do mundo e estudos moleculares

Tabela 2 -Distribuição dos sorotipos de Vibrio parahaemolyticus, de acordo com a concentração salina do meio de enriquecimento empregado.

\begin{tabular}{|c|c|c|c|}
\hline \multicolumn{4}{|c|}{ Água peptonada alcalina } \\
\hline \multicolumn{2}{|c|}{$\mathrm{NaCl}(1 \%)$} & \multicolumn{2}{|c|}{$\operatorname{NaCl}(3 \%)$} \\
\hline Sorotipo & $\overline{n^{0}}$ & sorotipo & $\mathrm{n}^{0}$ \\
\hline 01:K12 & 1 & 02:K3 & 4 \\
\hline 01:K32 & 1 & 02:K28 & 2 \\
\hline 01:K33 & 1 & $03: \mathrm{K} 5$ & 1 \\
\hline $02: \mathrm{K} 30$ & 1 & 03:K30 & 1 \\
\hline 03:K6 & 1 & $03: \mathrm{K} 57$ & 2 \\
\hline $03: \mathrm{K} 33$ & 2 & 04:K12 & 1 \\
\hline $03: \mathrm{K} 57$ & 3 & 04:K42 & 1 \\
\hline $03: K 72$ & 3 & 05:K17 & 6 \\
\hline 04:K34 & 2 & 08:K11 & 1 \\
\hline 05:K25 & 1 & 08:K39 & 1 \\
\hline 010:K25 & 1 & 010:K31 & 1 \\
\hline 010:K52 & 1 & 010:K60 & 1 \\
\hline 011:K19 & 2 & 011:K22 & 1 \\
\hline 01:KUT & 4 & 02:KUT & 1 \\
\hline 02:KUT & 2 & 04:KUT & 1 \\
\hline 08:KUT & 1 & 09:KUT & 1 \\
\hline 010:KUT & 16 & 010:KUT & 2 \\
\hline 011:KUT & 1 & 011:KUT & 3 \\
\hline
\end{tabular}

$\mathrm{n}^{0}=$ número de sorotipos caracterizados

KUT= Kuntypable (não tipável) têm demonstrado sua associação com o clone pandêmico 03:K6 $6^{18}$.

No Brasil, nas últimas duas décadas, os principais sorotipos identificados foram 02:K28, 03:K5, 010:K52, 05:K17 e 04:K12. Embora existam relatos da identificação do sorotipo 03:K6 a partir de amostras ambientais em nosso meio, desde este período não foi verificado nenhum registro dessa cepa pandêmica associado a casos humanos $^{61113}$.

Vibrio carchariae, espécie isolada de tubarões, é considerada microbiota normal, porém pode determinar quadro patológico quando o animal está sob estresse. A infecção humana pode ocorrer resultante de acidente com mordedura por este teleósteo, o que levanta a possibilidade de que a capacidade de agressão ocorra em condições oportunistas. Estudos realizados em algumas espécies de peixes de cultivo o apontam como agente etiológico de infecções ${ }^{59}$. Na presente investigação foi observada elevada frequiência de isolamento de Vibrio carchariae, o que indica a necessidade de avaliação da importância epidemiológica desse patógeno, dado o implemento da ostreicultura em nosso meio, especialmente para manipuladores que podem ferir-se no momento de abertura das valvas dos moluscos, expondo-se ao risco de infecção cutânea.

Em relação ao Vibrio alginolyticus é interessante ressaltar que a maior frequiência de isolamento ocorreu a partir do APA $3 \% \mathrm{NaCl}$ (29\%) corroborando com a característica halofílica deste patógeno. Sua importância epidemiológica está associada ao surgimento de infecções extra-intestinais em manipuladores de alimentos, caracterizadas por infecções autolimitadas de pele, olhos e ouvidos, particularmente em indivíduos portadores de síndromes crônico-degenerativas expostos ao ambiente marinho ${ }^{15}$.

Vibrio vulnificus foi detectado em $7,9 \%$ das amostras analisadas. Embora possa ser considerado reduzido, este resultado assume relevância epidemiológica, pois o microrganismo está associado a elevados índices de mortalidade (50\%) por sepse, tanto pela penetração cutânea em manipuladores, quanto após a ingestão de ostras in natura ${ }^{714}$

De um modo geral, verificamos a presença de Vibrio carchariae em $88 \%$ dos restaurantes incluídos na pesquisa. Vibrio parahaemolyticus e Vibrio alginolyticus foram isolados de $75 \%$ dos estabelecimentos, enquanto Vibrio vunificus foi isolado a partir de 53\% dos locais de coleta. As demais espécies (Vibrio cincinnatiensis, Vibrio fluvialis, Vibrio orientalis e Vibrio marinus) tiveram uma freqüência de isolamento considerada relativamente baixa.

Ressalta-se que cerca de $40 \%$ dos estabelecimentos estocavam as ostras em temperatura ambiente, o que constitui risco para a Saúde Pública, pois propicia condições de multiplicação de patógenos no alimento, além de acelerar sua decomposição e diminuir seu prazo de validade.

A adoção de medidas preventivas e corretivas baseadas nas BPM (Boas Práticas de Manufatura) pode auxiliar na redução destes patógenos, prevenindo a ocorrência de doenças de transmissão alimentar (DTA), a contaminação cruzada e recontaminação dos alimentos preparados. A utilização de depuração (natural 
ou artificial) para reduzir a carga microbiana do alimento, divulgação de informações sobre as corretas condições de estocagem (refrigeração a $4^{\circ} \mathrm{C}$ ), e manipulação em condições adequadas de higiene representam aspectos importantes para a comercialização de moluscos bivalves de qualidade e baixo risco para a saúde humana. No entanto, a cocção $\left(100^{\circ} \mathrm{C}\right)$ representa 0 método mais eficaz para que o alimento seja considerado seguro, sob o ponto de vista microbiológico. De um modo geral, ações interdisciplinares das Vigilâncias Sanitária e Epidemiológica podem gerar impactos positivos para a Saúde Pública nas várias dimensões da comercialização e consumo deste produto ${ }^{10}{ }^{11}$.

\section{REFERÊNCIAS}

1. Cabrera-Garcia ME. Vasquez-Salinas C, Quinones-Ramirez EI. Serologic and molecular characterization of Vibrio parahaemolyticus strains isolated from seawater and fish products of Gulf of Mexico. Applied Environmental Microbiology 70:6401-6406, 2004.

2. Davis CR, Heller LC, Peak KK, Wingfield DL, Goldstein-Hart CL, Bodager DW, Cannons AC, Amuso PT, Cattanii J. Real-Time PCR detection of the Thermostable Direct Hemolysin and Thermolabile Hemolysin genes in a Vibrio parabaemolyticus cultured from mussels and mussel homogenate associated with foodborne outbreak. Journal of Food Protection 67:1005-1008, 2004.

3. Kaysner CA, DePaola Jr A. Vibrio cholerae, V. parahaemolyticus, V. vulnificus, and Other Vibrio spp Bacteriological Analytical Manual, $8^{\text {th }}$ edition, http://www.cfsan.fda.gov/ ebam/bam-9.html, 2004.

4. Koelle K, Pascual M, Yunus M. Pathogen adaptation to seasonal forcing and climate change. Proceedings Bioliogical Sciences 272:971-977, 2005.

5. Lee KK, Liu PC, Chuang WH. Pathogenesis of gastroenteritis caused by Vibrio carchariae in cultured marine fish. Marine Biotechnology 4:267-277, 2002.

6. Magalhães V. Magalhães M, Marques LRM. Vibriões coléricos e não coléricos entre pacientes de boas condições sócio-econômicas durante a epidemia de coléra no Recife, Brasil. Revista do Instituto de Medicina Tropical de São Paulo 35: 345-346, 1993.
7. Nascimento SMM, Vieira RHSF, Theophilo GND. Vibrio vulnificus as a health hazard for shrimp consumers. Revista do Instituto de Medicina Tropical de São Paulo 43:263-266, 2001.

8. Nischibuchi M, Kaper JB. Thermostable Direct hemolysin gene of Vibrio parahaemolyticus: a virulence gene acquired by a marine bacterium. Infection and Immunology 63:2093-2099, 1995.

9. Pavia AT, Bryan JA, Maher KL, Hester, TR, Farmer Jr III JJ. Vibrio carchariae infection after a shark bite. Annals of International Medicine 111:85-86, 1989

10. Pereira CS. A cultura de mexilhões na Baía de Guanabara e suas implicações para a Saúde Pública - Contexto Político-Social e Microbiológico.Tese de Doutorado, Escola Nacional de Saúde Pública Sérgio Arouca, Rio de Janeiro, 2003.

11. Pereira CS, Viana CM, Rodrigues DP. Vibrio parahaemolyticus produtores de urease isolados a partir de ostras (Crassostrea rhizophorae) coletadas in natura em restaurantes e mexilhões (Perna perna) de banco natural. Ciência e Tecnologia de Alimentos 24:591-595, 2004.

12. Pruzzo C, Gallo G, Canesi L. Persistence of Vibrios in marine bivalves: the role of interactions with haemolymph components. Environmental Microbiology 7:761-772, 2005.

13. Rodrigues DP, Hofer E. Vibrio species from the water-oyster ecosystem of Sepetiba Bay in Rio de Janeiro State, Brazil. Revista de Microbiologia 4:332-338, 1986.

14. Rodrigues DP, Ribeiro RV, Hofer E. Analysis of some virulence factors of Vibrio vulnificus isolated from Rio de Janeiro, Brazil. Epidemiology and Infection 108: 463-467, 1992.

15. Rodrigues SMA, Gonçalves EGR, Mello DM, Oliveira EG, Hofer E. Pesquisa de bactérias do gênero Vibrio em feridas cutâneas de pescadores do município de Raposa-MA. Revista da Sociedade Brasileira de Medicina Tropical 34: 407-411, 2001.

16. Thompson FL, Iida T, Swings J. Biodiversity of Vibrios. Microbiology and Molecular Biology Reviews 68:403-431, 2004.

17. Vieira RHSF, Lima EA, Sousa DBR, Reis EMF, Costa RG, Rodrigues DP. Vibrio spp and Salmonella spp. presence and susceptibility in crabs Ucides cordatus. Revista do Instituto de Medicina Tropical de São Paulo 46: 179-182, 2004.

18. Hin-Chung W, Shu-Hui L, Tien-Kuei W, Chih-Lung L, Chien-Shun C, Ding-Ping L. Mitsuaki N, Bok-Kwon L. Characteristic of Vibrio parahaemolyticus 03:K6 from Asia. Applied and Environmental Microbiology 66: 3981-3986, 2000. 